\title{
Association of NTproBNP and cTnl with outpatient sudden cardiac death in hemodialysis patients: the Choices for Healthy Outcomes in Caring for ESRD (CHOICE) study
}

Rachel M. Kruzan ${ }^{1}$, Charles A. Herzog ${ }^{2}$, Aozhou Wu ${ }^{3}$, Yingying Sang ${ }^{4}$, Rulan S. Parekh ${ }^{5}$, Kunihiro Matsushita ${ }^{3,6}$, Seungyoung Hwang ${ }^{1}$, Alan Cheng ${ }^{7}$, Josef Coresh ${ }^{1,3,4,5}$, Neil R. Powe ${ }^{8}$ and Tariq Shafi ${ }^{6,9^{*}}$

\begin{abstract}
Background: Sudden cardiac death $(S C D)$ is the most common etiology of death in hemodialysis patients but not much is known about its risk factors. The goal of our study was to determine the association and risk prediction of SCD by serum N-terminal prohormone of brain natriuretic peptide (NTproBNP) troponin I (CTnl) in hemodialysis patients.

Methods: We measured NTproBNP and CTnl in 503 hemodialysis patients of a national prospective cohort study. We determined their association with SCD using Cox regression, adjusting for demographics, co-morbidities, and clinical factors and risk prediction using C-statistic and Net Reclassification Improvement (NRI).
\end{abstract}

Results: Patients' mean age was 58 years and $54 \%$ were male. During follow-up (median 3.5 years), there were 75 outpatient SCD events. In unadjusted and fully-adjusted models, NTproBNP had a significant association with the risk of SCD. Analyzed as a continuous variable, the risk of SCD increased $27 \%$ with each 2 -fold increase in NTproBNP (HR, 1.27 per doubling; $95 \% \mathrm{Cl}, 1.13-1.43 ; p<0.001)$. In categorical models, the risk of SCD was 3-fold higher in the highest tertile of NTproBNP $(>7,350 \mathrm{pg} / \mathrm{mL})$ compared with the lowest tertile $(<1,710 \mathrm{pg} / \mathrm{mL}$; HR for the highest tertile, 3.03; $95 \% \mathrm{Cl}, 1.56-5.89 ; p=0.001)$. Higher cTnl showed a trend towards increased risk of SCD in fully adjusted models, but was not statistically significant ( $\mathrm{HR}, 1.17$ per doubling; $95 \% \mathrm{Cl}, 0.98-1.40 ; p=0.08$ ). Sensitivity analyses using competing risk models showed similar results. Improvement in risk prediction by adding cardiac biomarkers to conventional risk factors was greater with NTproBNP (C-statistic for 3-year risk: 0.810; $95 \%$ Cl, 0.757 to 0.864 ; and continuous NRI: $0.270 ; 95 \% \mathrm{Cl}, 0.046$ to 0.495$)$ than with cTnl.

Conclusions: NTproBNP is associated with the risk of SCD in hemodialysis patients. Further research is needed to determine if biomarkers measurement can guide SCD risk prevention strategies in dialysis patients.

Keywords: Sudden Cardiac Death, Hemodialysis, NTproBNP, Troponin I

\footnotetext{
*Correspondence: tshafi@jhmi.edu

${ }^{6}$ Welch Center for Prevention, Epidemiology and Clinical Research, Johns

Hopkins University, Baltimore, MD, USA

${ }^{9}$ Department of Medicine, Division of Nephrology, Johns Hopkins University,

301 Mason Lord Drive, Suite, 2500 Baltimore, MD, USA

Full list of author information is available at the end of the article
} 


\section{Background}

At least one-quarter of deaths in dialysis patients are estimated to be from sudden cardiac death (SCD) [1]. This increased risk of SCD in dialysis patients is likely affected by the multiple, associated co-morbid conditions, such as diabetes [2] and hypertension [3], left ventricular hypertrophy [4], ischemic heart disease [5], inflammation [6] and perhaps the dialysis treatment itself with intermittent fluid and electrolyte fluctuations [2].

A large gap of knowledge still remains as to which dialysis patients are at the highest risk of suffering SCD. Cardiac biomarkers may identify patients with subclinical cardiovascular disease that are at increased risk for $\mathrm{SCD}$. The N-Terminal fragment of the pro-hormone brain natriuretic peptide (NTproBNP) is a marker of myocardial stretch and volume overload [7]. Serum cardiac troponin I (cTnI) is a marker of cardiac damage. Elevated cTnI levels in dialysis patients are associated with increased risk of all-cause and cardiovascular mortality, but few studies have investigated the association between these biomarkers and SCD in hemodialysis patients $[8,9]$.

The aim of our study was to determine if elevated levels of NTproBNP and cTnI are associated with increased risk for SCD in hemodialysis patients. We also evaluated whether these cardiac makers improve the risk prediction of SCD beyond conventional predictors in hemodialysis patients.

\section{Methods}

\section{Study design}

The Choices for Healthy Outcomes in Caring for ESRD (CHOICE) Study is a longitudinal, prospective cohort study of 1041 patients starting dialysis that were recruited from 81 dialysis centers in 19 states. Eligibility criteria included dialysis initiation in preceding 3 months, age 18 years or older, ability to speak English or Spanish, and ability to consent. Each participant completed informed consent. The participants were enrolled from October 1995 to June 1998 and were on average 45 days post-dialysis initiation. A specimen bank was established for all Dialysis Clinic, Inc. (DCI) participants. Our analysis included 503 hemodialysis participants with available stored specimens. The Johns Hopkins Medicine Institutional Review Board and the clinical centers' review boards approved the study and all participants provided informed consent.

\section{Cardiac biomarkers (Serum NTproBNP and cTnl)}

We collected blood samples prior to routine outpatient dialysis session, centrifuged within 30-45 min of collection, and sent them overnight on ice to the central laboratory. We divided each sample into multiple vials and stored at $-80{ }^{\circ} \mathrm{C}$ till they were thawed and aliquoted for this study. We measured NT-pro-BNP using a onestep sandwich chemiluminescent immunoassay also

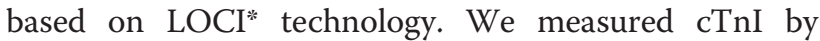
homogeneous, sandwich chemiluminescent immunoassay based on $\mathrm{LOCI}^{*}$ technology. Both NTproBNP and cTnI were measured on the Dimension Vista System at the University of Maryland School of Medicine, Baltimore, Maryland. The coefficient of variation $(\mathrm{CV})$ for NT-pro-BNP was $5.0 \%$ at $107.2 \mathrm{pg} / \mathrm{mL}$ and $1.6 \%$ at $275 \mathrm{pg} / \mathrm{mL}$ and $1.2 \%$ at $3,313 \mathrm{pg} / \mathrm{mL}$. The reliability correlation coefficient for NT-pro-BNP was 0.998 . The CV for cTnI was $9.1 \%$ at $0.090 \mathrm{ng} / \mathrm{mL}, 5.9 \%$ at $1.08 \mathrm{ng} / \mathrm{mL}$ and $1.6 \%$ at $4.87 \mathrm{ng} / \mathrm{mL}$. The reliability correlation coefficient for cTnI in a $5 \%$ sample of masked duplicate specimens was 0.969 .

\section{Outcome}

The primary outcome for this study was outpatient SCD defined as an out-of-hospital deaths including deaths that occurred in an emergency department or one in which the patient was reported to be "dead on arrival" with the following codes noted in the National Death Index death certificate data: ICD-9 390-398, 402 or 404-429; and ICD-10, I00-I09, I11, I13 and I20-I51, as previously described [6]. We excluded deaths with hyperkalemia, sepsis or malignancy listed as a contributing cause of death or if the death occurred while under hospice care.

\section{Other covariates}

We collected data on participants' age, sex, race and body mass index (BMI). We adjudicated baseline comorbidities including prevalent cardiovascular disease and left ventricular hypertrophy (as assessed by electrocardiograms) by abstraction of dialysis unit records, hospital discharge summaries, medication lists, consultation notes, diagnostic imaging, and cardiac imaging reports and Index of Coexistent Disease (ICED) scoring. For this index, comorbid conditions, including diabetes mellitus, ischemic heart disease, congestive heart failure, hypertension, peripheral vascular disease, and other conditions, were determined present by two trained nurses, and then, the severity of each comorbid condition for each patient was calculated using Index of Disease Severity (IDS) and Index of Physical Impairment (IPI) (30). These two scores were then used to calculate the ICED score, which serves as a validated medical recordderived index that captures both presence and severity of comorbid conditions ${ }^{19,20,30}$. ICED scores range from 0 to 3 , with 3 as the highest severity level. We abstracted antihypertensive medication use at baseline from patients' charts and obtained routine laboratory data from medical records. We measured serum albumin $(\mathrm{CV}$, $1.9 \%)$ in the same specimen as NTproBNP and cTnI at 
University of Minnesota, Minneapolis, Minnesota. We also used data on C-reactive protein, interleukin- 6 and p-selectin that had been previously measured for research $[10,11]$. Other laboratory data measured in routine clinical care included hemoglobin, calcium, phosphate, blood urea nitrogen, creatinine, glucose, potassium and bicarbonate. These laboratory data were obtained from the same time as cardiac biomarker assessment.

\section{Statistical analysis}

We compared the baseline characteristics of the participants across categories of NTproBNP and cTnI using chi-squared test for categorical variables and t-tests for continuous variables. Missing data for variables were as follows: educational status (2.8\%), smoking history (2.8 \%), BMI (5.6\%) systolic blood pressure (3.8 \%), serum potassium, calcium and phosphate $(6.8 \%)$ and serum bicarbonate $(12 \%)$. Missing data values were imputed with 10 data replicates using multiple imputation by the chained equations method implemented by the ice program in Stata. We modeled NTproBNP and cTnI as continuous variables after natural log transformation and as categorical variables. We categorized NTproBNP as tertiles and cTnI as a low, mid and high category. The low cTnI group included those with cTnI below detection limit; $(<0.015 \mathrm{ng} / \mathrm{mL} ; n=336)$. Remaining patients are divided into two groups at the median with the mid category referring to group with detectable values but below median $(<0.040 \mathrm{ng} / \mathrm{mL} ; n=85)$ and high category referring to the group with values at or above median $(\geq 0.040 \mathrm{ng} / \mathrm{mL} ; n=82)$. We visualized the association between NTproBNP and cTnI and outcomes by calculating incidence rates for SCD adjusted for age, sex and race using a Poisson regression model with biomarkers modeled as linear spline with 2 knots corresponding to the categories. We used Cox proportional hazards regression to analyze the association between the biomarkers and SCD. We assessed proportional hazards assumptions graphically and by tests of Schoenfeld residuals. We used hazard ratios (HRs) to quantify the associations of biomarkers with SCD after adjustment for a priori defined confounders, including demographic characteristics [age, sex, race (white or other)] and clinical factors [smoking status (ever versus never), ICED score, diabetes, cardiovascular disease, left ventricular hypertrophy, congestive heart failure, BMI and systolic blood pressure], laboratory tests (hemoglobin, serum albumin, serum potassium, serum bicarbonate, serum corrected calcium and serum phosphate) and $\beta$-blocker use. We conducted sensitivity analyses further adjusting for biomarkers previously associated with SCD in CHOICE study (i.e., CRP, IL-6, and p-selectin) and accounting for the competing risk of death from other causes using competing-risks regression based on Fine and Gray's proportional subhazards model. In exploratory analyses we further determined SCD risk association within subgroups by testing for interactions with age, sex, race, cardiovascular disease, diabetes, serum albumin, serum potassium and serum bicarbonate, with continuous variables categorized above or below median. We evaluated risk prediction by NTproBNP and cTnI over 5years by calculating $\mathrm{C}$ statistic and net reclassification improvement (NRI) [12, 13]. We assessed model calibration using modified Hosmer-Lemeshow statistic [14, 15]. We performed all statistical analyses using Stata software, version 12.1 (Stata Corp.). We defined statistical significance as $\mathrm{p}<0.05$ using two-tailed tests.

\section{Results}

Baseline characteristics

The final study sample comprised of 503 hemodialysis patients. Compared to the overall cohort, the included patients were less likely to be White and had higher urea creatinine, potassium, calcium, phosphate and albumin and lower hemoglobin and Kt/Vurea (Additional file 1: Table S1). The average age of the participants was 58 years and $54 \%$ were men. At baseline, $57 \%$ of the participants had diabetes, $56 \%$ had cardiovascular disease, and $24 \%$ had a history of myocardial infarction. Table 1 summarizes the baseline characteristics of the participants according to categories of NTproBNP and cTnI. Patients with higher NTproBNP and cTnI were older, more likely to have a history of cardiovascular disease, and have elevated IL-6 levels. In addition, patients with higher NTproBNP were more likely to be White, had lower body BMI and higher CRP whereas those with higher cTnI were more likely to be male.

\section{Association of NTproBNP and cTnl with SCD}

The 75 SCD events occurred over 1,814 person-year of follow-up (median 3.5 years) with an incidence rate of 41.4 SCD events over 1000 person-years. The causes of death in these 75 patients, cross-tabulated by the causes listed in the National Death Index and Center for Medicare and Medicaid Services (CMS) death notification form (Form 2746) are presented in Additional file 1: Table S2. Fig. 1 presents the incidence rate of SCD adjusted for age, sex and race, demonstrating a linear increase in SCD incidence rate with NTproBNP and a relatively flat association with cTnI. In unadjusted models and minimally adjusted models, both NTproBNP and cTnI were associated with risk of SCD (Table 2). After adjustment for demographics, clinical factors, comorbidities, laboratory tests and $\beta$-blocker use, NTproBNP continued to have a statistically significant association $[\mathrm{HR}, 95 \%$ confidence interval $(\mathrm{CI})]$ with SCD $[1.27(1.13-1.43) ; \quad p<0.001]]$ whereas as the 
Table 1 Characteristics of 503 Hemodialysis Patients by Levels of NTproBNP and cTnl

\begin{tabular}{|c|c|c|c|c|c|c|c|c|c|}
\hline \multirow[b]{3}{*}{ Characteristic } & \multirow[b]{3}{*}{ Overall } & \multicolumn{4}{|c|}{ NTproBNP (pg/mL) Categories } & \multicolumn{4}{|c|}{ Troponin I (ng/mL) Categories } \\
\hline & & \multirow[b]{2}{*}{ Low } & \multirow[b]{2}{*}{ Mid } & \multirow[b]{2}{*}{ High } & \multirow[b]{2}{*}{$p$} & \multirow{2}{*}{$\begin{array}{l}\text { Below Detection Limit } \\
\text { Low }\end{array}$} & \multicolumn{2}{|l|}{ Detectable } & \multirow[b]{2}{*}{$p$} \\
\hline & & & & & & & Mid & High & \\
\hline $\begin{array}{l}\text { Range, minimum } \\
\text { to maximum }\end{array}$ & & $59-1710$ & $1728-7269$ & $7350-273502$ & - & $<0.015$ & $0.015-0.039$ & $0.04-3.09$ & - \\
\hline$N(\%)$ & $503(100)$ & $168(33.4)$ & $168(33.4)$ & $167(33.2)$ & - & $336(66.8)$ & $85(16.9)$ & $82(16.3)$ & - \\
\hline $\begin{array}{l}\text { TNI, median } \\
\left(25^{\text {th }}-75^{\text {th }}\right. \\
\text { percentiles }) \\
n g / m L\end{array}$ & $<0.015(<0.015-0.023)$ & $<0.015$ & $<0.015(<0.015-0.020)$ & $0.021(<0.015-0.049)$ & - & $<0.015$ & $0.023(0.020-0.029)$ & $0.085(0.052-0.162)$ & - \\
\hline $\begin{array}{l}\text { NTproBNP, } \\
\text { median }\left(25^{\text {th }}-75^{\text {th }}\right. \\
\text { percentiles) } \mathrm{pg} / \mathrm{mL}\end{array}$ & 3138(1233-9835) & $822.5(489.5-1238)$ & $3145.5(2364-4622)$ & 14735(9835-24240) & - & $2205(945-5670.5)$ & $7166(2326-16018)$ & 10242(4187-23407) & - \\
\hline \multicolumn{10}{|l|}{ Demographics } \\
\hline Age, years & $57.8(14.7)$ & $52.7(13.8)$ & $59.8(15.2)$ & $60.9(13.6)$ & $<0.001$ & $56.1(15.4)$ & $60.3(13.1)$ & $62.1(11.9)$ & $<0.001$ \\
\hline White & $321(63.8)$ & $99(58.9)$ & $101(60.1)$ & $121(72.5)$ & 0.017 & $225(67.0)$ & $50(58.8)$ & $46(56.1)$ & 0.107 \\
\hline Male & $273(54.3)$ & $91(54.2)$ & $88(52.4)$ & $94(56.3)$ & 0.773 & $164(48.8)$ & $55(64.7)$ & $54(65.9)$ & 0.002 \\
\hline \multicolumn{10}{|l|}{$\begin{array}{l}\text { Clinical } \\
\text { Characteristics }\end{array}$} \\
\hline $\begin{array}{l}\text { Body Mass } \\
\text { Index, } \mathrm{Kg} / \mathrm{m}^{2}\end{array}$ & $27.4(7.1)$ & $28.2(7.8)$ & $28.1(7.5)$ & $25.8(5.6)$ & 0.002 & $27.6(7.3)$ & $27.0(6.7)$ & 26.9 (6.9) & 0.297 \\
\hline \multicolumn{10}{|l|}{$\begin{array}{l}\text { Cause of End } \\
\text { Stage Renal Disease }\end{array}$} \\
\hline Diabetes mellitus & $248(49.3)$ & 77 (45.8) & $82(48.8)$ & 89 (53.3) & 0.389 & $157(46.7)$ & $46(54.1)$ & $45(54.9)$ & 0.259 \\
\hline Hypertension & $86(17.1)$ & $21(12.5)$ & $27(16.1)$ & $38(22.8)$ & 0.041 & $50(14.9)$ & $18(21.2)$ & $18(22.0)$ & 0.172 \\
\hline Glomerulonephritis & $74(14.7)$ & $36(21.4)$ & $25(14.9)$ & $13(7.8)$ & 0.002 & $58(17.3)$ & $9(10.6)$ & $7(8.5)$ & 0.068 \\
\hline Other & 95 (18.9) & $34(20.2)$ & $34(20.2)$ & $27(16.2)$ & 0.547 & $71(21.1)$ & $12(14.1)$ & $12(14.6)$ & 0.189 \\
\hline ICED = 3 & $147(29.3)$ & $41(24.4)$ & $46(27.5)$ & $60(35.9)$ & 0.057 & $97(29.0)$ & $20(23.5)$ & 30 (36.6) & 0.175 \\
\hline Diabetes & 287 (57.2) & 85 (50.6) & 95 (56.9) & $107(64.1)$ & 0.045 & $180(53.7)$ & $54(63.5)$ & $53(64.6)$ & 0.087 \\
\hline $\begin{array}{l}\text { Cardiovascular } \\
\text { Disease }\end{array}$ & $279(55.6)$ & $64(38.1)$ & $102(61.1)$ & $113(67.7)$ & $<0.001$ & $165(49.3)$ & $58(68.2)$ & $56(68.3)$ & $<0.001$ \\
\hline $\begin{array}{l}\text { Congestive } \\
\text { Heart Failure }\end{array}$ & $247(49.2)$ & $58(34.5)$ & $80(47.9)$ & $109(65.3)$ & $<0.001$ & $146(43.6)$ & $54(63.5)$ & $47(57.3)$ & 0.001 \\
\hline $\begin{array}{l}\text { Coronary Heart } \\
\text { Disease }\end{array}$ & $209(41.6)$ & $42(25)$ & $77(46.1)$ & $90(53.9)$ & $<0.001$ & $114(34.0)$ & $47(55.3)$ & $48(58.5)$ & $<0.001$ \\
\hline $\begin{array}{l}\text { Myocardial } \\
\text { Infarction }\end{array}$ & $120(23.9)$ & $20(11.9)$ & $51(30.5)$ & $49(29.3)$ & $<0.001$ & $68(20.3)$ & $23(27.1)$ & 29 (35.4) & 0.012 \\
\hline $\begin{array}{l}\text { Left Ventricular } \\
\text { Hypertrophy }\end{array}$ & $137(27.3)$ & $43(25.6)$ & $41(24.6)$ & $53(31.7)$ & 0.281 & $74(22.1)$ & $29(34.1)$ & $34(41.5)$ & 0.001 \\
\hline
\end{tabular}


Table 1 Characteristics of 503 Hemodialysis Patients by Levels of NTproBNP and cTnl (Continued)

\begin{tabular}{|c|c|c|c|c|c|c|c|c|c|}
\hline $\begin{array}{l}\text { Time Since } \\
\text { Start of Dialysis, } \\
\text { Months }\end{array}$ & $5.0(1.6)$ & $5.0(1.5)$ & $4.7(1.5)$ & $5.2(1.6)$ & 0.189 & $4.9(1.5)$ & $5.3(1.5)$ & $5.1(1.7)$ & 0.168 \\
\hline \multicolumn{10}{|l|}{ Laboratory Tests } \\
\hline $\begin{array}{l}\text { Blood Urea } \\
\text { Nitrogen, mg/dL }\end{array}$ & $57.8(15.1)$ & $57.6(15.3)$ & $58.3(15.4)$ & $57.6(14.8)$ & 0.998 & $57.3(15.5)$ & $59.3(14.9)$ & $58.4(14.1)$ & 0.482 \\
\hline Kt $/ N_{\text {UREA }}$ & $1.3(0.302)$ & $1.3(0.324)$ & $1.3(0.278)$ & $1.3(0.303)$ & 0.250 & $1.3(0.316)$ & $1.3(0.255)$ & $1.3(0.292)$ & 0.788 \\
\hline $\begin{array}{l}\text { Creatinine, } \\
\mathrm{mg} / \mathrm{dL}\end{array}$ & $8.0(2.9)$ & $8.2(2.8)$ & $8.2(3.2)$ & $7.6(2.5)$ & 0.081 & $8.1(2.9)$ & $7.9(2.7)$ & $7.6(2.8)$ & 0.311 \\
\hline Potassium, mEq/L & $4.7(0.665)$ & $4.6(0.584)$ & $4.7(0.712)$ & $4.7(0.680)$ & 0.036 & $4.7(0.642)$ & $4.7(0.689)$ & $4.7(0.733)$ & 0.665 \\
\hline Glucose, mg/dL & $167.0(103.0)$ & $162.3(79.0)$ & $164.0(82.7)$ & $174.8(137.2)$ & 0.780 & $159.9(83.4)$ & $178.4(120.0)$ & $183.9(145.3)$ & 0.222 \\
\hline $\begin{array}{l}\text { Bicarbonate, } \\
\mathrm{mEq} / \mathrm{L}\end{array}$ & $20.4(2.9)$ & $20.7(2.7)$ & $20.0(3.0)$ & $20.5(2.9)$ & 0.510 & $20.4(2.9)$ & $20.7(2.5)$ & $20.2(3.4)$ & 0.919 \\
\hline $\begin{array}{l}\text { Hemoglobin, } \\
\text { g/dL }\end{array}$ & $11.0(1.3)$ & $11.2(1.5)$ & $10.9(1.3)$ & $10.8(1.3)$ & 0.003 & $11.0(1.4)$ & $11.2(1.2)$ & $10.8(1.4)$ & 0.686 \\
\hline $\begin{array}{l}\text { Corrected } \\
\text { Calcium, mg/dL }\end{array}$ & $9.8(0.883)$ & $9.7(0.854)$ & $9.8(0.954)$ & $9.8(0.839)$ & 0.471 & $9.8(0.881)$ & $9.8(0.918)$ & $9.6(0.844)$ & 0.050 \\
\hline Phosphate, mg/dL & $5.5(1.7)$ & $5.5(1.6)$ & $5.5(1.8)$ & $5.6(1.6)$ & 0.348 & $5.5(1.7)$ & $5.8(1.6)$ & $5.6(1.9)$ & 0.283 \\
\hline Albumin, g/dL & $3.5(0.549)$ & $3.7(0.503)$ & $3.5(0.568)$ & $3.4(0.547)$ & $<0.001$ & $3.5(0.533)$ & $3.5(0.621)$ & $3.5(0.538)$ & 0.559 \\
\hline $\begin{array}{l}\text { CRP, mg/L (median, } \\
25^{\text {th }}-75^{\text {th }} \\
\text { percentiles) }\end{array}$ & $0.445(0.203-1.219)$ & $0.382(0.158-0.779)$ & $0.486(0.224-1.317)$ & $\begin{array}{l}0.51 \\
(0.217-1.496)\end{array}$ & 0.007 & $0.441(0.195-1.229)$ & $0.431(0.148-1.04)$ & $0.489(0.222-1.155)$ & 0.980 \\
\hline $\begin{array}{l}\mathrm{IL}-6, \mathrm{pg} / \mathrm{mL} \\
\text { (median, } 25^{\text {th }}-75^{\text {th }} \\
\text { percentiles) }\end{array}$ & $4.8(2.8-8.2)$ & $3.8(2.3-5.6)$ & $5.2(2.7-8.9)$ & $6.2(3.6-11.5)$ & $<0.001$ & $4.3(2.6-7.4)$ & $5.3(3.4-9.0)$ & $6.1(3.6-11.7)$ & 0.008 \\
\hline $\begin{array}{l}\text { P-Selectin, } \mathrm{ng} / \mathrm{ml} \\
\text { (median, } 25^{\text {th }}-75^{\text {th }} \\
\text { percentiles) }\end{array}$ & $97.2(75.6-126.0)$ & $93.4(74.0-125.9)$ & 96(73.9-124.1) & $98.7(79.4-130.2)$ & 0.526 & $96.3(76.2-127.7)$ & $94.7(72.2-117.0)$ & $105.5(78.2-124.5)$ & 0.627 \\
\hline \multicolumn{10}{|l|}{$\begin{array}{l}\text { Antihypertensive } \\
\text { Medications, \% }\end{array}$} \\
\hline$\beta$-blockers & $123(24.5)$ & $36(21.4)$ & $40(23.8)$ & $47(28.1)$ & 0.350 & $84(25.0)$ & $21(24.7)$ & $18(22.0)$ & 0.846 \\
\hline ACE-inhibitors & 147 (29.2) & $40(23.8)$ & $51(30.4)$ & $56(33.5)$ & 0.136 & 87 (25.9) & $29(34.1)$ & $31(37.8)$ & 0.058 \\
\hline $\begin{array}{l}\text { Calcium Channel } \\
\text { Blockers }\end{array}$ & $309(61.4)$ & $105(62.5)$ & $109(64.9)$ & $95(56.9)$ & 0.304 & $205(61.0)$ & $60(70.6)$ & $44(53.7)$ & 0.077 \\
\hline
\end{tabular}

Abbreviations: Troponin I, TNl; Hazard Ratio, HR; N-terminal pro-brain natriuretic peptide, NTproBNP

For TNI, low category refers those patients with TNI below the limit of detection $(<0.015 \mathrm{ng} / \mathrm{mL} ; n=336)$. Remaining patients are divided into two groups at the median. Mid category refers to the group below median TNI for those with detectable values $(<0.040 \mathrm{ng} / \mathrm{mL} ; n=85)$ and high category refers to those with values at or above median $(\geq 0.040 \mathrm{ng} / \mathrm{mL} ; n=82)$

For NTproBNP, low, mid and high category refers to the lowest, middle and highest tertiles of NTproBNP

$P$-values represent $\mathrm{p}$-trend by linear regression for continuous variables and chi-square $\mathrm{p}$-values for categorical variables 
a

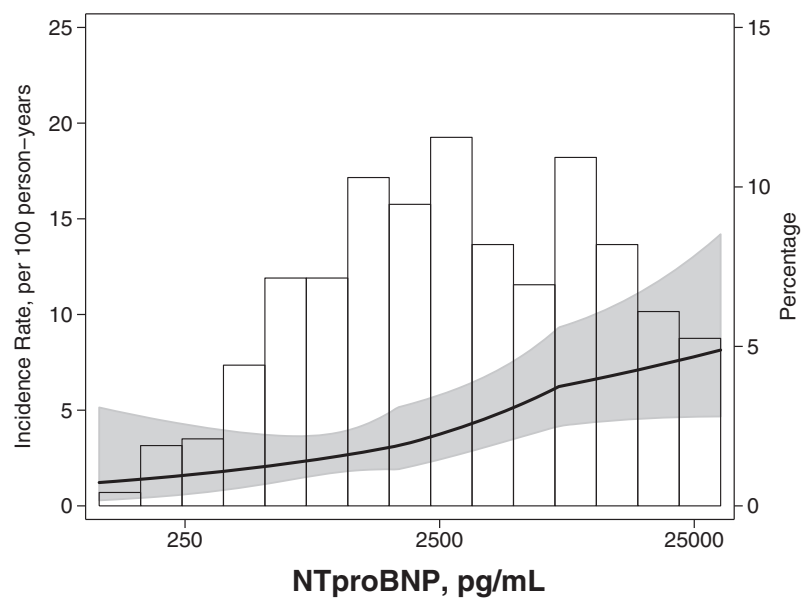

b

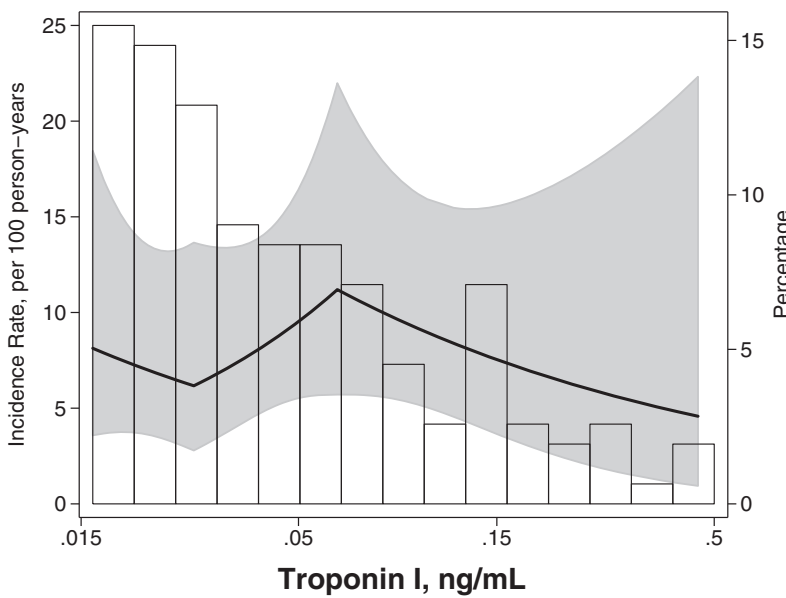

Fig. 1 Adjusted incidence rate of sudden cardiac death in 503 participants of the CHOICE Study. Incidence rate per 100 person years adjusted for age, sex and race. Results are presented separately for (a) N-terminal pro-brain natriuretic peptide (NTproBNP) and (b) cardiac troponin I (cTnl). Line represents hazard ratio and shaded area represents the $95 \%$ confidence interval. Vertical bars represent the distribution of the biomarkers. Data are limited to $\geq 0.5^{\text {th }}$ percentile and $\leq 99.5^{\text {th }}$ percentiles

association between cTnI and SCD was not statistically significant [1.17 (0.98-1.40); $p=0.08]$. Similar results were noted in the categorical analysis (Table 2). In the fully adjusted models, compared to the lowest tertile of NTproBNP, those in the highest tertile had a more than 3-fold higher risk of SCD [3.03 (1.56-5.89); $p=0.001]$. Compared to the low cTnI category (undetectable cTnI), those in the mid (detectable and below median) and high cTnI category (detectable and above median) had a non-significant trend towards increased risk of SCD in the fully adjusted models.

\section{Sensitivity analyses of the association between NTproBNP} and CTNI and SCD

Further adjustment for markers of inflammation (CRP, IL6 and p-selectin) did not significantly change the magnitude or the direction of association (data not presented). Analyses using competing risks models showed results similar to the primary analysis (Additional file 1: Table S3).

\section{Exploratory analyses of the association between NTproBNP and CTnl and SCD}

The subgroup analyses should be interpreted with caution due to small sample size and multiple comparisons. There were no significant interactions in the models for NTproBNP (Fig. 2a) but there was suggestion of effect modification by cTnI and sex (p-interaction $=0.02$ ), baseline cardiovascular disease $(\mathrm{p}$-interaction $=0.01)$, serum albumin ( $\mathrm{p}$-interaction $=0.008)$, serum potassium ( $\mathrm{p}$ interaction $=0.01)$ and bicarbonate $(\mathrm{p}$-interaction $=0.02)$.

\section{Risk prediction of SCD with NTproBNP and cTnl}

Compared to the fully adjusted model, the improvement in 3-year and 5-year risk prediction was greater with NTproBNP than cTnI (Table 3). Addition of both NTproBNP and cTnI to the model did not lead to further improvement in risk prediction.

\section{Discussion}

In this national prospective cohort study of incident dialysis patients, we found a significant association between NTproBNP levels and the risk of outpatient SCD. Patients in the highest tertile of NTproBNP $(>7,350 \mathrm{pg} /$ $\mathrm{mL}$ ) had a more than 3-fold higher risk of SCD compared with those in the lowest tertile $(<1,710 \mathrm{pg} / \mathrm{mL})$. NTproBNP also improved risk prediction of SCD with improvement in 3-year and 5-year NRI. Higher cTnI $(>0.04 \mathrm{ng} / \mathrm{mL})$ was also associated with a $91 \%$ higher risk of SCD although it was of borderline statistical significance.

NTproBNP is a marker of myocardial stretch and correlates with reduced left ventricular function and volume overload in dialysis patients [3, 16, 17]. A number of previous studies have reported the association between elevated NTproBNP and cTnI and all-cause and cardiovascular mortality [18-20]. However, only a few prior studies have studied the association between these markers and SCD in dialysis patients. In the German Diabetes and Dialysis Study (4D-Study), NTproBNP above the fourth quartile $(\geq 9,252 \mathrm{pg} / \mathrm{mL})$ was associated with 2-fold higher risk of SCD compared with the lowest quartile. However, the study only included patients with diabetes. In a study of 230 peritoneal dialysis patients, 
Table 2 Association of NTproBNP and CTnl with Sudden Cardiac Death among 503 Hemodialysis Patients of the CHOICE Study

\begin{tabular}{|c|c|c|c|c|c|c|c|c|c|c|c|}
\hline & & & & Model 1 & & Model 2 & & Model 3 & & Model 4 & \\
\hline & Range & $\mathrm{N}$ (events) & CrudeIR & HR $(95 \% \mathrm{Cl})$ & $p$ & HR (95\% Cl) & $p$ & $\mathrm{HR}(95 \% \mathrm{Cl})$ & $p$ & HR $(95 \%$ Cl) & $p$ \\
\hline \multicolumn{12}{|c|}{ NTproBNP, pg/mL } \\
\hline Continuous $^{a}$ & & $503(75)$ & & $1.33(1.21-1.46)$ & $<0.001$ & $1.29(1.17-1.42)$ & $<0.001$ & $1.28(1.14-1.44)$ & $<0.001$ & $1.27(1.13-1.43)$ & $<0.001$ \\
\hline \multicolumn{12}{|l|}{ Categorical $^{b, d}$} \\
\hline Low Category & 59-1710 & $168(13)$ & 19.0 & Reference & & Reference & & Reference & & Reference & \\
\hline Mid Category & $1728-7269$ & $168(22)$ & 35.3 & $1.99(1.25-3.14)$ & 0.003 & $1.99(1.16-3.41)$ & 0.012 & $1.67(1.01-2.77)$ & 0.045 & $1.39(0.79-2.44)$ & 0.252 \\
\hline High Category & $7350-273502$ & $167(40)$ & 78.9 & $4.49(2.61-7.71)$ & $<0.001$ & $3.90(2.07-7.34)$ & $<0.001$ & $3.32(1.67-6.59)$ & 0.001 & $3.03(1.56-5.89)$ & 0.001 \\
\hline$p$-trend & & & & $<0.001$ & & $<0.001$ & & 0.001 & & 0.001 & \\
\hline \multicolumn{12}{|c|}{ Troponin I, ng/mL } \\
\hline Continuous $^{a}$ & & $503(75)$ & & $1.19(1.06-1.32)$ & 0.002 & $1.22(1.07-1.38)$ & 0.002 & $1.18(1.02-1.36)$ & 0.027 & $1.17(0.98-1.40)$ & 0.084 \\
\hline \multicolumn{12}{|l|}{ Categorical b, c } \\
\hline Low Category & $<0.015$ & $336(41)$ & 32.8 & Reference & & Reference & & Reference & & Reference & \\
\hline Mid Category & $0.015-0.039$ & $85(18)$ & 57.5 & $1.82(1.06-3.10)$ & 0.029 & $1.83(1.04-3.20)$ & 0.036 & $1.56(0.88-2.80)$ & 0.128 & $1.62(0.89-2.95)$ & 0.11 \\
\hline High Category & $0.040-3.09$ & $82(16)$ & 64.0 & $2.14(1.46-3.13)$ & $<0.001$ & $2.48(1.51-4.06)$ & $<0.001$ & $1.98(1.15-3.39)$ & 0.013 & $1.91(0.98-3.72)$ & 0.058 \\
\hline$p$-trend & & & & $<0.001$ & & $<0.001$ & & 0.011 & & 0.048 & \\
\hline
\end{tabular}

Abbreviations: Troponin I, cTnl; Hazard Ratio, HR; N-terminal pro-brain natriuretic peptide, NTproBNP. Incidence rate per 1000 person-years

a Hazard ratio per doubling of the marker; modeled as $\ln ($ marker $) / \ln (2)$. Modeled using Cox proportional hazards regression

${ }^{\mathrm{b}}$ Hazard ratio with the low category as the reference group. Modeled using Cox proportional hazards regression

' For cTnl, low category refers those patients with TNI below the limit of detection $(<0.015 \mathrm{ng} / \mathrm{mL} ; n=336)$. Remaining patients are divided into two groups at the median. Mid category refers to the group below

median $\mathrm{cTnl}$ for those with detectable values $(<0.040 \mathrm{ng} / \mathrm{mL} ; n=85)$ and high category refers to those with values at or above median $(\geq 0.040 \mathrm{ng} / \mathrm{mL} ; n=82)$

${ }^{\mathrm{d}}$ For NTproBNP, low, mid and high category refers to the lowest, middle and highest tertiles of NTproBNP

Model 1: Unadjusted

Model 2: Adjusted for demographics including age, sex and race

Model 3: Adjusted for variables in model 2 + clinical factors including smoking status (ever versus never), Index of Coexistent Disease (ICED) score, diabetes, cardiovascular disease, congestive heart failure, body mass index and systolic blood pressure

Model 4: Adjusted for variables in model $3+$ left ventricular hypertrophy, $\beta$-blocker use and laboratory tests including hemoglobin, serum albumin, serum potassium, serum bicarbonate, serum corrected calcium and serum phosphate 


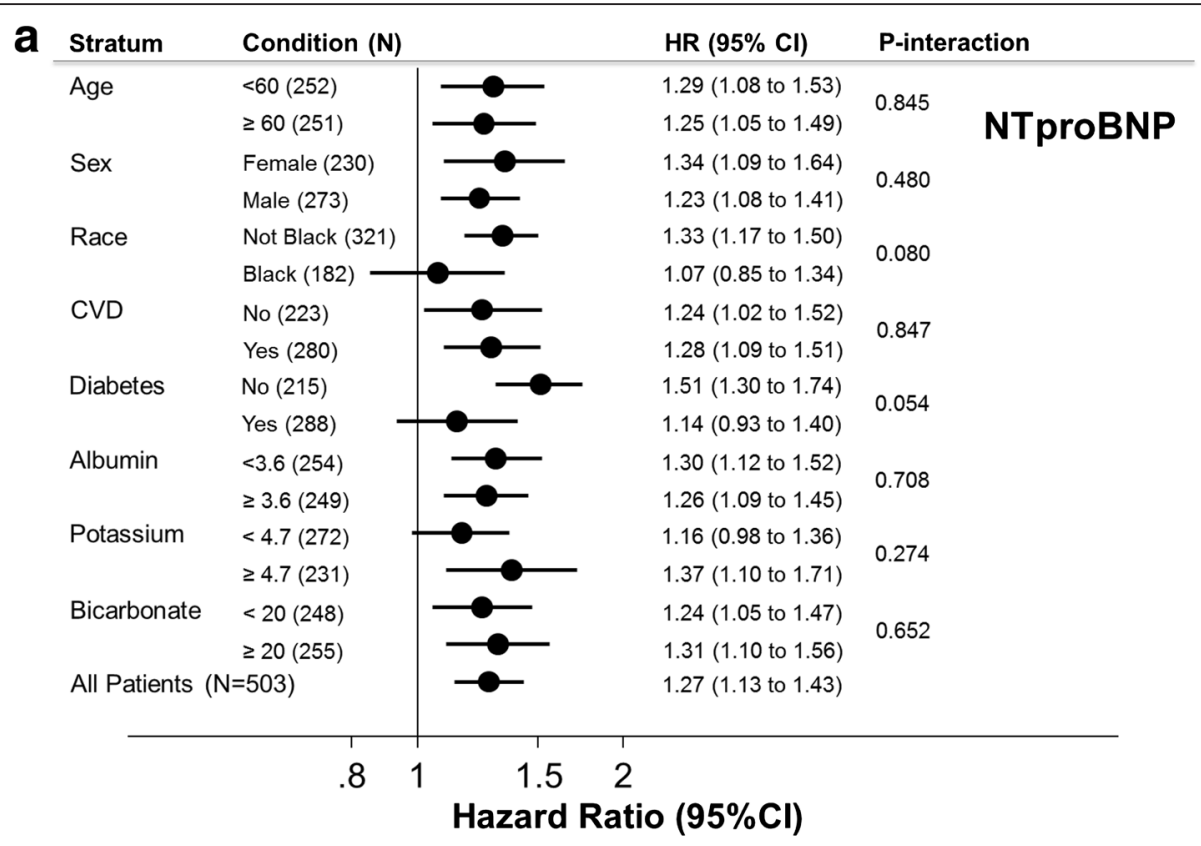

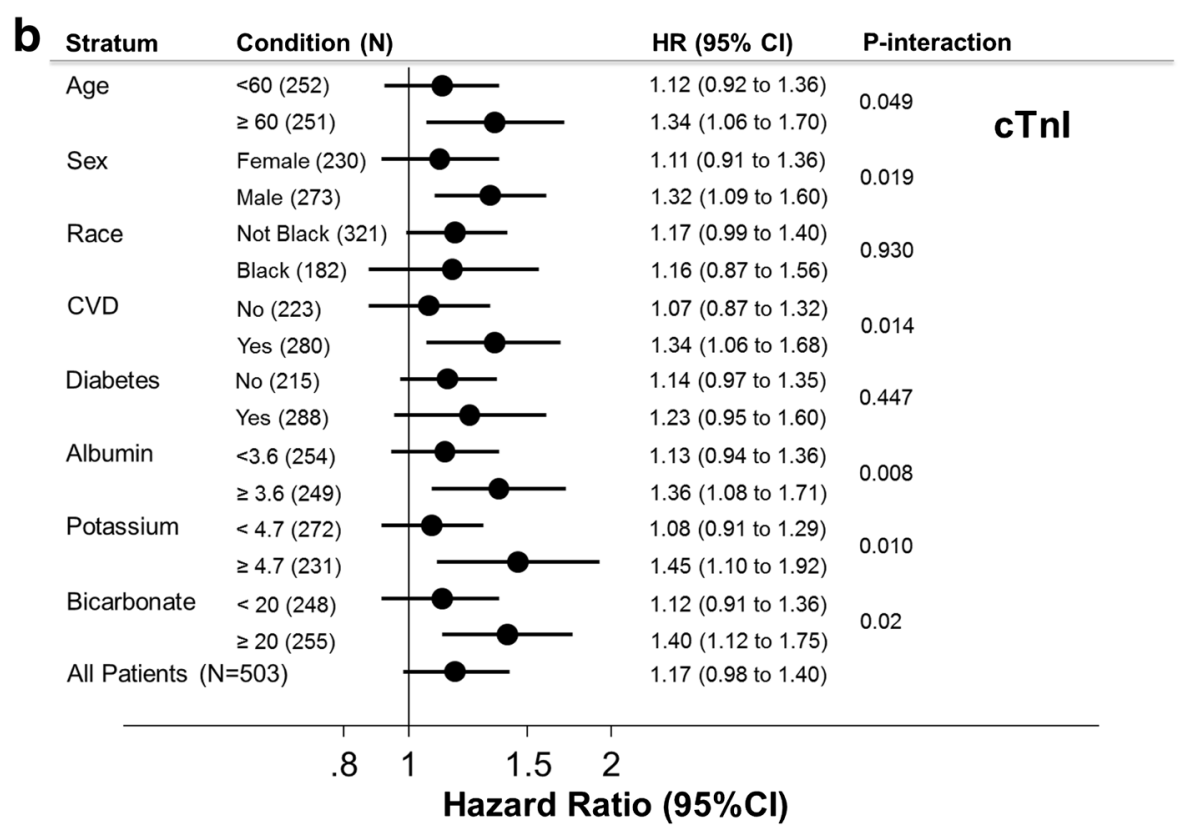

Fig. 2 Subgroup analysis of the association between (a) NTproBNP and (b) CTnl and sudden cardiac death in 503 participants of the CHOICE Study. Hazard ratios are adjusted for variable in Model 4: demographics (age, sex and race), clinical factors [smoking status (ever versus never), Index of Coexistent Disease (ICED) score, diabetes, cardiovascular disease, congestive heart failure, body mass index and systolic blood pressure], left ventricular hypertrophy, $\beta$-blocker use and laboratory tests including hemoglobin, serum albumin, serum potassium, serum bicarbonate, serum corrected calcium and serum phosphate

NTproBNP but not troponin $\mathrm{T}$ was associated with an increased risk of SCD [3]. Our study extends these findings to a national cohort of US dialysis patients and shows a stronger association of NTproBNP compared with cTnI with SCD.

cTnI is an inhibitory protein within the troponintropomyosin complex that regulates striated muscle contraction [21]. The troponin complex is released in damaged cardiac muscle and serum levels are sensitive markers of cardiac injury [21, 22]. In our study, the findings of weaker association between cTnI and SCD compared with NTproBNP could reflect a greater risk of arrhythmia and SCD with volume overload and ventricular stretch detected by 
Table 3 Risk Prediction for Sudden Cardiac Death with NTproBNP and cTnl in 503 Hemodialysis Patients of the CHOICE Study

\begin{tabular}{|c|c|c|c|c|}
\hline & Model $4^{a}$ & + NTproBNP & $+c \operatorname{Tnl}$ & +NTproBNP and cTnl \\
\hline \multicolumn{5}{|l|}{ 3-Year Risk } \\
\hline C-Statistic & 0.790 (0.728 to 0.851$)$ & 0.810 (0.757 to 0.864$)$ & 0.791 (0.732 to 0.849 ) & 0.810 (0.756 to 0.864$)$ \\
\hline Change in C-Statistic ${ }^{b}$ & Ref & $0.020(-0.016$ to 0.057$)$ & $0.001(-0.019$ to 0.021$)$ & $0.020(-0.017$ to 0.057$)$ \\
\hline NRI, Binary & Ref & 0.125 (0.032 to 0.219$)$ & $0.033(-0.021$ to 0.088$)$ & 0.133 (0.039 to 0.227 ) \\
\hline NRI, Continuous & Ref & $0.262(-0.048$ to 0.572$)$ & $0.125(-0.186$ to 0.436$)$ & $0.212(-0.098$ to 0.522$)$ \\
\hline \multicolumn{5}{|l|}{ 5-Year Risk } \\
\hline C-Statistic & 0.773 (0.723 to 0.823 ) & 0.797 (0.751 to 0.843 ) & 0.778 (0.730 to 0.827 ) & 0.797 (0.751 to 0.843 ) \\
\hline Change in C-Statistic & Ref & $0.024(-0.004$ to 0.053$)$ & $0.006(-0.009$ to 0.021$)$ & $0.024(-0.005$ to 0.053$)$ \\
\hline NRI, Binary & Ref & $0.063(-0.028$ to 0.154$)$ & $0.001(-0.065$ to 0.067$)$ & $0.072(-0.020$ to 0.164$)$ \\
\hline NRI, Continuous & Ref & 0.270 (0.046 to 0.495$)$ & $0.018(-0.207$ to 0.243$)$ & 0.356 (0.132 to 0.581$)$ \\
\hline
\end{tabular}

Abbreviations: SCD sudden cardiac death; NTproBNP, and N-terminal prohormone of brain natriuretic peptide; CTnl cardiac troponin l; CVD cardiovascular disease; $D M$ diabetes mellitus; $C$-statistic, concordance statistic, NRI net reclassification index

a Model 4: Adjusted for demographics (age, sex and race), clinical factors [smoking status (ever versus never), Index of Coexistent Disease (ICED) score, diabetes, cardiovascular disease, congestive heart failure, body mass index and systolic blood pressure], left ventricular hypertrophy, $\beta$-blocker use and laboratory tests including hemoglobin, serum albumin, serum potassium, serum bicarbonate, serum corrected calcium and serum phosphate

${ }^{\mathrm{b}}$ Change in C-statistic by adding biomarker to the variables in Model 4

NTproBNP versus elevation of cTnI which could be from myocardial injury but could also reflect decreased renal clearance [23]. In previous dialysis studies, prevalence of elevated cTnI is lower than prevalence of elevated troponin $\mathrm{T}$ [18] and elevated cTnI levels have been inconsistently associated with increased risk of death. [23, 24] Whether these findings represent biological associations or the effect of assay variability at the low threshold will require future studies with comparison of different cTnI assay techniques, including the high-sensitivity troponin I assays [25].

In addition to evaluating NTproBNP and cTnI as a risk factor for SCD, we assessed its role in improving risk prediction. To our knowledge, prior studies of cardiac biomarkers in hemodialysis patients have not assessed improvement in risk prediction by cardiac biomarkers over traditional risk factors. In a study by Goldstein et al. using electronic medical record data, blood pressure, ultrafiltration and serum albumin predicted short-term (within a day of last outpatient hemodialysis) SCD in dialysis patients but cardiac biomarkers were not measured. [26] The rate of SCD in dialysis patients, 41 per 1000 person-years in our study, was substantially higher than that reported in the general population [27]. Implantable cardioverterdefibrillators (ICDs) can prevent SCD but are associated with a higher risk of infection [28, 29]. There are no randomized controlled data to guide primary prevention ICDs in this high risk population. Improvement in risk prediction of SCD by NTproBNP may help with identifying the patients at highest risk of SCD and facilitate their enrollment in future trials of SCD prevention.
There are some limitations to our study. First, we had a single measurement of biomarkers in stored specimens. The serum concentrations in individuals may change over time and the long storage time may effect serum concentrations. Second, our definition of SCD was based on location at time of death and the results may not apply to inpatient deaths many of which may be due to ventricular arrhythmias. The proportion of SCD was lower in our cohort (75/503; $15 \%)$ versus that reported by USRDS (26.5 \%). This could be due to difference in SCD definition (Additional file 1: Table S4) or due to relatively healthier patients in our cohort that survived to $\sim 6$ months when blood samples were obtained. Exclusion of inpatient deaths is likely to underestimate the risk. Third, patients with available samples may have been in better health compared to the overall cohort as they had higher baseline serum albumin and creatinine than included patients. It is possible that the associations may have been even stronger in the full cohort. Finally, even though we adjusted for a number of confounders, the possibility of uncontrolled confounding remains from factors, such as echo or magnetic resonance imaging based left ventricular mass and dialysate composition, which were not available in this study. These limitations are counterbalanced by our prospective study design with detailed assessments of baseline comorbidities complete and extensive information on covariates and inflammatory markers which are not available on most registry based retrospective dialysis cohorts. The use of NDI data rather than Form 2746 data is also an important strength of this study. Form 2746 is filled out by the primary nephrologist in the dialysis unit, sometimes 
weeks after death, and they may not know of the cause of death. NDI uses death certificate data which is from providers who were closer to patients' care at the time of death. This approach reduces the risk of misclassification of outcomes (Additional file 1: Table S2).

\section{Conclusions}

In conclusion, our study demonstrates a significant association between NTproBNP and SCD and suggests that elevated NTproBNP level in dialysis patients is a potent predictor for SCD. SCD is a potentially modifiable cause of death in dialysis patients. Risk-centered approaches have the potential to identify patients at highest risk for SCD and test therapies for its prevention.

\section{Additional file}

Additional file 1: Supplemental Tables 1-4. (DOCX $21 \mathrm{~kb}$ )

\section{Abbreviations}

SCD: sudden cardiac death; NTproBNP: N-Terminal fragment of the prohormone brain natriuretic peptide; cTnl: cardiac troponin I; CHOICE: Choices for Healthy Outcomes in Caring for ESRD; DCl: Dialysis Clinic, Inc.; CV: coefficient of variation; ICED: Index of Coexistent Disease; BMI: Body mass index; NRI: net reclassification improvement; CMS: Center for Medicare and Medicaid Services; HR: hazard ratio; Cl: confidence interval.

\section{Competing interests}

Dr. Shafi reports receiving an honorarium from Siemens. Remaining authors declare that they have no relevant financial interests.

CHOICE was supported by R01-HS-008365 (Agency for Healthcare Quality and Research AHRQ) from 7/1994 to 6/1999, by RO1-HL-62985 (National Heart, Lung, and Blood Institute (NHLBI) from 9/00 to 6/06, R01-DK-059616 (National Institute of Diabetes \& Digestive \& Kidney Diseases NIDDK) from 9/2000 to 6/2005 and by R01-DK-080123 from 8/2008 to 6/2015 (National Institute of Diabetes \& Digestive \& Kidney Diseases NIDDK).

\section{Authors' contributions}

RK and TS conceived the study design and drafted the manuscript. TS, AW, $\mathrm{SH}$ conducted statistical analyses. All authors interpreted the data, read the manuscript, made meaningful changes and approved the final manuscript. Dr. Shafi was supported by K23-DK-083514 and National Kidney Foundation of Maryland Professional Development Award.

Dr. Powe was supported by R01-DK-080123.

Research reported in this publication was supported by the National Institute of Diabetes and Digestive and Kidney Diseases of the National Institutes of Health. The content is solely the responsibility of the authors and does not necessarily represent the official views of the National Institutes of Health. The reagents for troponin I and NTproBNP were provided by Siemens to the University of Maryland, where the measurements were performed. Siemens had no role in the design, analysis, and interpretation of data or the preparation of this manuscript.

Parts of this work were presented at the National Kidney Foundation's Spring Clinical Meeting April 22-26, 2014 at Las Vegas, NV.

\section{Acknowledgement}

We thank the patients, staff, laboratory, and physicians of Dialysis Clinic Inc. (DCI) for their participation in the CHOICE Study.

We thank the Cardiovascular Endpoint Committee: Bernard G. Jaar, MD, MPH; Michael J. Choi, MD; Josef Coresh, MD, PhD; Joseph A. Eustace, MD, MHS; Nancy E. Fink, MPH; Caroline Fox, MD, MPH; Melanie H. Katzman, MD, MHS; Michael J. Klag, MD, MPH; Yongmei Liu, MD, PhD; J. Craig Longenecker, MD, PhD; Michal Melamed, MD, MHS; Laura C. Plantinga, ScM; Neil R. Powe, MD, MPH, MBA; Renuka Sothinathan, MD, MHS; Richard M. Ugarte, MD, MHS and Gayanne Yenokian, MD.

\section{Author details}

'Department of Medicine, Johns Hopkins University, Baltimore, MD, USA. ${ }^{2}$ Department of Medicine, Division of Cardiology, Hennepin County Medical Center, University of Minnesota, Minneapolis, MN, USA. ${ }^{3}$ Department of Epidemiology, Johns Hopkins Bloomberg School of Public Health, Baltimore, MD, USA. ${ }^{4}$ Department of Biostatistics, Johns Hopkins Bloomberg School of Public Health, Baltimore, MD, USA. ${ }^{5}$ Departments of Medicine and Pediatrics, University of Toronto, Toronto, Canada. ${ }^{6}$ Welch Center for Prevention, Epidemiology and Clinical Research, Johns Hopkins University, Baltimore, MD, USA. ${ }^{7}$ Department of Medicine, Division of Cardiology, Johns Hopkins University, Baltimore, MD, USA. ${ }^{8}$ Department of Medicine, University of California, San Francisco, CA, USA. 'Department of Medicine, Division of Nephrology, Johns Hopkins University, 301 Mason Lord Drive, Suite, 2500 Baltimore, MD, USA.

Received: 15 June 2015 Accepted: 12 February 2016

Published online: 20 February 2016

\section{References}

1. U S Renal Data System, USRDS 2013 Annual Data Report: Atlas of Chronic Kidney Disease and End-Stage Renal Disease in the United States, National Institutes of Health, National Institute of Diabetes and Digestive and Kidney Diseases, Bethesda, MD, 2013

2. Green D, Roberts PR, New DI, Kalra PA. Sudden cardiac death in hemodialysis patients: an in-depth review. American journal of kidney diseases : the official journal of the National Kidney Foundation. 2011;57(6):921-9.

3. Wang AY, Lam CW, Chan IH, Wang M, Lui SF, Sanderson JE. Sudden cardiac death in end-stage renal disease patients: a 5-year prospective analysis. Hypertension. 2010;56(2):210-6.

4. Paoletti E, Specchia C, Di Maio G, Bellino D, Damasio B, Cassottana P, et al. The worsening of left ventricular hypertrophy is the strongest predictor of sudden cardiac death in haemodialysis patients: a 10 year survey. Nephrology, dialysis, transplantation : official publication of the European Dialysis and Transplant Association - European Renal Association. 2004;19(7):1829-34.

5. Sakhuja R, Shah AJ, Hiremath S, Thakur RK. End-stage renal disease and sudden cardiac death. Cardiac Electrophysiology Clinics. 2009;1 11):61-77.

6. Parekh RS, Plantinga LC, Kao WH, Meoni LA, Jaar BG, Fink NE, et al. The association of sudden cardiac death with inflammation and other traditional risk factors. Kidney international. 2008;74(10):1335-42.

7. Davenport A, Sayed RH, Fan S. Is extracellular volume expansion of peritoneal dialysis patients associated with greater urine output? Blood Purif. 2011;32(3):226-31.

8. Sun $L$, Sun $Y$, Z Zhao $X$, Xu C, Chen D, Li L, et al. Predictive role of BNP and NT-proBNP in hemodialysis patients. Nephron Clinical practice. 2008;110(3): c178-184.

9. Winkler K, Wanner C, Drechsler C, Lilienthal J, Marz W, Krane V, et al. Change in N-terminal-pro-B-type-natriuretic-peptide and the risk of sudden death, stroke, myocardial infarction, and all-cause mortality in diabetic dialysis patients. European heart journal. 2008;29(17):2092-9.

10. Banerjee T, Kim SJ, Astor B, Shafi T, Coresh J, Powe NR. Vascular access type, inflammatory markers, and mortality in incident hemodialysis patients: the Choices for Healthy Outcomes in Caring for End-Stage Renal Disease (CHOICE) Study. Am J Kidney Dis. 2014;64(6):954-61.

11. Shafi T, Jaar BG, Plantinga LC, Fink NE, Sadler JH, Parekh RS, et al. Association of residual urine output with mortality, quality of life, and inflammation in incident hemodialysis patients: the Choices for Healthy Outcomes in Caring for End-Stage Renal Disease (CHOICE) Study. Am J Kidney Dis. 2010;56(2):348-58.

12. Pencina MJ, D'Agostino RB. Overall $\mathrm{C}$ as a measure of discrimination in survival analysis: model specific population value and confidence interval estimation. Statistics in medicine. 2004;23(13):2109-23.

13. Pencina MJ, D'Agostino Sr RB, Steyerberg EW. Extensions of net reclassification improvement calculations to measure usefulness of new biomarkers. Statistics in medicine. 2011;30(1):11-21.

14. D'Agostino Sr RB, Vasan RS, Pencina MJ, Wolf PA, Cobain M, Massaro JM, et al. General cardiovascular risk profile for use in primary care: the Framingham Heart Study. Circulation. 2008;117(6):743-53.

15. Hosmer DW, Hosmer T, Le Cessie S, Lemeshow S. A comparison of goodness-of-fit tests for the logistic regression model. Statistics in medicine. 1997;16(9):965-80 
16. Breidthardt T, Burton JO, Odudu A, Eldehni MT, Jefferies $H$, Mclntyre CW. $\mathrm{N}$-terminal Pro-B-type natriuretic peptide and its correlation to haemodialysis-induced myocardial stunning. Nephron Clinical practice. 2013;123(1-2):

$118-22$.

17. Papakrivopoulou E, Lillywhite $\mathrm{S}$, Davenport A. Is N-terminal probrain-type natriuretic peptide a clinically useful biomarker of volume overload in peritoneal dialysis patients? Nephrology, dialysis, transplantation : official publication of the European Dialysis and Transplant Association - European Renal Association. 2012;27(1):396-401

18. Apple FS, Murakami MM, Pearce LA, Herzog CA. Predictive value of cardiac troponin I and $T$ for subsequent death in end-stage renal disease. Circulation. 2002;106(23):2941-5.

19. Mallamaci F, Zoccali C, Parlongo S, Tripepi G, Benedetto FA, Cutrupi S, et al. Troponin is related to left ventricular mass and predicts all-cause and cardiovascular mortality in hemodialysis patients. American journal of kidney diseases : the official journal of the National Kidney Foundation. 2002;40(1): 68-75.

20. Michos ED, Berger Z, Yeh HC, Suarez-Cuervo C, Wilson LM, Stacy S, Bass EB: Cardiac Troponins Used as Diagnostic and Prognostic Tests in Patients With Kidney Disease. In: Cardiac Troponins Used as Diagnostic and Prognostic Tests in Patients With Kidney Disease. Rockville (MD); 2014.

21. Cuschieri A, Adamson GD. Multimedia article. Laparoscopic transection choledochoduodenostomy. Surgical endoscopy. 2005;19(5):728.

22. Adams 3rd JE, Bodor GS, Davila-Roman VG, Delmez JA, Apple FS, Ladenson $\mathrm{JH}$, et al. Cardiac troponin I. A marker with high specificity for cardiac injury. Circulation. 1993;88(1):101-6.

23. Abbas NA, John Rl, Webb MC, Kempson ME, Potter AN, Price CP, et al. Cardiac troponins and renal function in nondialysis patients with chronic kidney disease. Clinical chemistry. 2005;51(11):2059-66.

24. Khan IA, Wattanasuwan N, Mehta NJ, Tun A, Singh N, Singh HK, et al. Prognostic value of serum cardiac troponin I in ambulatory patients with chronic renal failure undergoing long-term hemodialysis: a two-year outcome analysis. Journal of the American College of Cardiology. 2001; 38(4):991-8.

25. Jaffe AS. Testing the wrong hypothesis: the failure to recognize the limitations of troponin assays. Journal of the American College of Cardiology. 2001;38(4):999-1001.

26. Goldstein BA, Chang TI, Mitani AA, Assimes TL, Winkelmayer WC. Near-term prediction of sudden cardiac death in older hemodialysis patients using electronic health records. Clin J Am Soc Nephrol. 2014;9(1):82-91.

27. Pun PH, Smarz TR, Honeycutt EF, Shaw LK, Al-Khatib SM, Middleton JP. Chronic kidney disease is associated with increased risk of sudden cardiac death among patients with coronary artery disease. Kidney Int. 2009;76(6): 652-8.

28. Hickson LJ, Gooden JY, Le KY, Baddour LM, Friedman PA, Hayes DL, et al. Clinical presentation and outcomes of cardiovascular implantable electronic device infections in hemodialysis patients. Am J Kidney Dis. 2014;64(1): 104-10.

29. Prutkin JM, Reynolds MR, Bao H, Curtis JP, Al-Khatib SM, Aggarwal S, et al. Rates of and factors associated with infection in 200909 Medicare implantable cardioverter-defibrillator implants: results from the national cardiovascular data registry. Circulation. 2014;130(13):1037-43.

\section{Submit your next manuscript to BioMed Central and we will help you at every step:}

- We accept pre-submission inquiries

- Our selector tool helps you to find the most relevant journal

- We provide round the clock customer support

- Convenient online submission

- Thorough peer review

- Inclusion in PubMed and all major indexing services

- Maximum visibility for your research

Submit your manuscript at www.biomedcentral.com/submit
Biomed Central 